\title{
Food security of food recipients of a food pantry and soup kitchen
}

\author{
Tamara Y Mousa and Jeanne H Freeland-Graves* \\ Department of Nutritional Sciences 103 West 24th Street, Painter 444, Nutritional Sciences A2703, \\ The University of Texas at Austin, Austin, TX 78712, USA
}

Submitted 17 February 2018: Final revision received 2 November 2018: Accepted 14 November 2018: First published online 8 February 2019

\begin{abstract}
Objective: To discern the impact of food donations provided by a food pantry and soup kitchen on food security.

Design: In this cross-sectional study, participants completed a demographic questionnaire, core food security module, FFQ and list of food donations. The FFQ was utilized to assess diet quality as estimated via the 2010 Healthy Eating Index. Setting: Clients were selected randomly from a food pantry and soup kitchen in Central Texas, USA.

Participants: A total of 222 adults.

Results: Approximately $73 \%$ of participants lacked food security. Compared with the food secure, the food insecure consisted of $61 \%$ men, $42 \%$ Caucasians, $56 \%$ single and $67 \%$ homeless. Also, of the food insecure, $60 \%$ were soup kitchen clients and $64 \%$ had an annual income $<\$$ US $1000(P<0 \cdot 01)$. The probability of food insecurity was reduced by $\geq 1 \cdot 17$-fold when the total dietary intake included the food donations, as these were rich in fruits, total vegetables and grains, dairy and protein foods $(P<0 \cdot 05)$.

Conclusions: Food insecurity was quite prevalent in this sample of individuals who visited food pantries and soup kitchens. The addition of food donations improved the quality of the participants' total diet and had a positive influence on food security. Thus, community organizations should financially support these food assistance agencies and strive to offer a variety of healthy and tasty foods in adequate quantities to provide optimum diet quality.
\end{abstract}

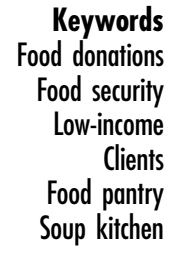

Food insecurity is a socio-economic inability to purchase uncontaminated, nutritionally healthy food in sufficient amounts $^{(1)}$. Worldwide, $10.9 \%$ of the population lacks food security ${ }^{(2)}$. In 2014-2016, 5.5, $12 \cdot 1$ and $20.0 \%$ of individuals residing in Latin America, Asia and Africa were food insecure, respectively ${ }^{(2)}$. In Europe, a recent report indicated that food insecurity was $0.7 \%$ in the Commonwealth of Independent States, $1.7 \%$ in the European Union and $5.2 \%$ in South-East Europe ${ }^{(3)}$. In North America, the current rate of food insecurity varies considerably according to region. In Canada, it is as low as $10 \%$ in British Columbia or high as $51 \%$ in Nunavut ${ }^{(4)}$. In the USA, the rate of food insecurity has varied slightly in the past decade: $\sim 12 \%$ in $2001, \sim 17 \%$ in $2009^{(5)}$ and $13.4 \%$ in $2015^{(6)}$. These data suggest that food insecurity is a global nutritional issue that affects both developed and developing countries.

Food insecurity exists in all ethnic and age groups. In the USA, a national survey by Coleman-Jensen et al. reported that food insecurity was more prevalent among African Americans (21.6\%) and Hispanics (20.5\%) than
Caucasians (10.2\%) and Asians $(10 \cdot 4 \%)^{(6)}$. Food insecurity also has been found in all ages, including children and the elderly $^{(7)}$. A cross-sectional study in the Southwest USA investigated food insecurity in fifty Mexican mother-child dyads who resided in homes in colonies on the Texas border. A lack of food security was observed in the majority of the mothers (80\%) and two-thirds of the children $^{(8)}$. Clearly, solutions to minimize the incidence of this societal issue in the USA are warranted.

The US Government has launched a variety of emergency programmes that have been successful in providing food to the low-income population. These include the Supplemental Nutrition Assistance Program (SNAP; formerly Food Stamps), the Special Supplemental Nutrition Program for Women, Infants, and Children, Meals on Wheels and the School Breakfast/Lunch Program ${ }^{(9)}$. SNAP has been particularly effective. For example, Mabli and Worthington reported that food insecurity diminished by $12.5 \%$ in 3000 families who were enrolled in SNAP for 6 months $^{(10)}$. Yet not everyone can enrol in SNAP, such as those with a criminal record or without citizenship. Thus, 
another alternative to reduce food insecurity in the lowincome population is to provide food donations, wherein surplus food is collected from retail stores and vendors and redistributed to those in need. Numerous organizations are involved in food redistribution at the global level. Examples are: Banco de Alimentos de Buenos Aires in Argentina $^{(11)}$, Food Angel Program in Hong Kong ${ }^{(12)}$, Food from the Heart in Singapore ${ }^{(13)}$, Leket Food Bank of Israel $^{(14)}$, Wa'hab in Qatar ${ }^{(15)}$, Food Bank Namibia ${ }^{(16)}$, Trussell Trust in England ${ }^{(17)}$, Instock in the Netherlands $^{(18)}$, CulinARy MiSfiTS in Germany ${ }^{(19)}$, Zero Desperdicio in Portugal ${ }^{(19)}$, SecondBite in Australia $^{(20)}$ and Second Harvest in Canada ${ }^{(21)}$.

In the USA, examples of charitable agencies that annually reallocate large quantities of food include Feeding America ( 181 million tons $)^{(22)}$, Donate Don't Dump $(\sim 295 \text { tons })^{(23)}$ and, at the state level, Capital Area Food Bank of Texas (20 711 tons) $)^{(24,25)}$. Other effective organizations are found in Florida ${ }^{(26)}$, New Jersey ${ }^{(27)}$, Washington $^{(28)}$, Alabama ${ }^{(29)}$, North Carolina ${ }^{(30)}$ and New York $^{(31,32)}$. Collectively, these non-government programmes are critical for reducing food insecurity in the USA.

Various factors are associated with lack of food security; these include low socio-economic status ${ }^{(33)}$, lack of employment ${ }^{(34)}$ and high prices of healthy foods such as fruits and vegetables ${ }^{(35,36)}$. A cross-sectional study of fortyone caregivers for children reported that $46 \%$ were food insecure, even though $34 \%$ received food assistance. The households that lacked food security consumed foods of low nutritional value such as convenience and fast foods. The risk of food insecurity increased by onefold in families who had insufficient resources and limited food preparation supplies to buy and cook the food $(P<0.05)^{(37)}$.

To date, the role that food donations from pantries and soup kitchens play in improving the food security of their clients has not been explored fully. Thus, the objective of the present study was to discern the impact of food donations on food security.

\section{Materials and methods}

\section{Design}

A total of 317 individuals (aged $\geq 18$ years) who receive free food benefits were recruited from a food pantry and soup kitchen in Central Texas, USA, to participate in a cross-sectional study. A demographic questionnaire, nutrition knowledge scale, Core Food Security Module (CFSM), FFQ and a list of food donations were administered to the participants. The CFSM measured the degree of food security in participants over the past $30 \mathrm{~d}$. The FFQ estimated energy and dietary intake of the total diet for the previous month. The list of food donations concerned characteristics of the food benefits (type, amount and frequency). Diet quality was estimated for the base diet and total diet (base diet plus food donations) via the Healthy Eating Index-2010 (HEI-2010). Serving sizes of food groups were determined using MyPlate. Reported descriptions of the food donations were validated by taking photographs via use of a smart phone.

\section{Participants}

A total of 317 food recipients were recruited and 222 adults agreed to participate. Of these, 112 were from a food pantry that offered free foods and 110 from a soup kitchen that provided a free meal. None of the participants used both food services; thus, the clients of the food pantries and soup kitchen did not overlap. The nature of the research was explained and a signed consent form was obtained. Participants completed the questionnaires and received a compensation of \$US 10 .

\section{Tools of assessment}

The demographic questionnaire is a self-reported instrument developed and tested by the authors ${ }^{(38)}$. It consists of twenty-five items regarding information about age, sex, ethnicity, weight, height, educational level, marital status, occupation and socio-economic status.

The nutrition knowledge scale was developed and validated by the authors to evaluate knowledge regarding weight loss, healthy food intake, fast foods, dietary guidelines and macro- and micronutrients ${ }^{(39)}$. This scale consists of twenty multiple-choice and true/false questions and its score ranges from 0 to 20 , with a higher score indicating a better level of nutrition knowledge (Cronbach's $\alpha=0 \cdot 7)^{(38,39)}$.

The CFSM is a questionnaire established and validated by the US Department of Agriculture to evaluate the status of household food security. It consists of eighteen questions about the availability of food at home and money to purchase food ${ }^{(40)}$. The overall score of this instrument ranges between 0 and 10 for households without children, and from 0 to 18 for those with children ${ }^{(40)}$. A higher score reflects lower food security status ${ }^{(40)}$. Total household score was compared with a scaled value that reflected the level of food security (0-3). A value of 0 designates lack of food insecurity; scales of 1,2 and 3 indicate food insecurity without hunger, food insecurity with moderate hunger and food insecurity with severe hunger, respectively $^{(40)}$.

The FFQ is a 195-item tool developed and tested by the authors in low-income, tri-ethnic women (Cronbach's $\alpha=0.69)^{(41)}$. This tool assesses the frequency and portions of food intake over the past $30 \mathrm{~d}$. The consumption frequency ranges from 'never or $<1$ per month' to ' $2+$ times per day'. The size of servings consumed ranges between 'small' and 'extra large'.

The list of food donations requires food recipients to describe the type (packaged, canned and/or fresh) and 
Table 1 Participant characteristics, according to food security status, of adult clients $(n$ 222) from a food pantry and soup kitchen in Central Texas, USA, in September and October 2015

\begin{tabular}{|c|c|c|c|c|c|c|c|}
\hline \multirow[b]{2}{*}{ Variable } & \multicolumn{3}{|c|}{ Food secure $(n 60)$} & \multicolumn{3}{|c|}{ Food insecure ( $n$ 162) } & \multirow[b]{2}{*}{$P$ value } \\
\hline & Mean & SE & Range & Mean & $\mathrm{SE}$ & Range & \\
\hline Age (years) & $46 \cdot 85^{a}$ & 1.68 & $20-78$ & $48 \cdot 70^{\mathrm{a}}$ & 0.96 & $21-81$ & 0.326 \\
\hline Residence in USA (years) & $34.06^{\mathrm{a}}$ & 2.88 & $1-78$ & $44.70^{\mathrm{b}}$ & 1.28 & $1-81$ & 0.000 \\
\hline $\mathrm{BMl}\left(\mathrm{kg} / \mathrm{m}^{2}\right)$ & $21 \cdot 10^{\mathrm{a}}$ & 0.78 & $20 \cdot 74-56 \cdot 61$ & $26 \cdot 89^{b}$ & 0.49 & $16 \cdot 61-51 \cdot 88$ & 0.019 \\
\hline Annual income (\$US) & $9272 \cdot 85^{a}$ & $1605 \cdot 77$ & $0-60000$ & $4962 \cdot 14^{b}$ & $752 \cdot 13$ & $0-50000$ & 0.007 \\
\hline CFSM score* & $3.07^{a}$ & 0.28 & $0-7$ & $8.99^{b}$ & 0.17 & $3-18$ & 0.000 \\
\hline Total HEI-2010 score $†$ & $67 \cdot 13^{\mathrm{a}}$ & 0.98 & $34 \cdot 8-79 \cdot 8$ & $62.95^{\mathrm{b}}$ & 0.55 & $37 \cdot 4-79 \cdot 8$ & 0.000 \\
\hline
\end{tabular}

a,b Mean values within a row with unlike superscript letters were significantly different $(P \leq 0.05)$.

${ }^{*}$ Core Food security Module (CFSM) score ranges between 0 and 10 for a household without children, and from 0 to 18 for a home with children. A higher score reflects greater food insecurity ${ }^{(27)}$.

†Total Healthy Eating Index-2010 (HEl-2010) score range is 0-100. A higher score reflects greater diet quality ${ }^{(32)}$.

quantity and/or portion size of the donated food/meal, and the frequency of attending the food pantry or soup kitchen. Validity of the food donations received was evaluated by comparing the collected data with photographs of the foods.

Dietary intake of food was tabulated for total (daily base diet plus food donations) and base diets (diet prior to donations) and food donations received by clients. Nutrients and energy were estimated by the software FoodWorks 8 Professional $^{(42)}$ which is based on the US Department of Agriculture database.

Choose MyPlate is a tool developed to guide individuals to live a healthy lifestyle based on one's age, sex, height, weight and physical activity. This tool was used to measure portion size equivalents for each food group based on daily recommended intakes ${ }^{(43)}$. Furthermore, the 2015-2020 Dietary Guidelines for Americans ${ }^{(44)}$ were used to estimate the number of servings of vegetables, fruits, refined and whole grains, dairy products, beans and meat, and empty calories. Choose MyPlate was utilized to quantify the serving size of each food group eaten by each client on a daily basis. Then the amount consumed was compared with the 2015-2020 US dietary guidelines ${ }^{(44)}$ to assess the nutritional status of the participants.

The Healthy Eating Index-2010 (HEI-2000) was used to estimate diet quality for the base and total daily food consumption of the clients ${ }^{(45)}$. This index evaluates adequate and moderate intake of foods and nutrients based on their compliance with the US dietary guidelines ${ }^{(44)}$. This scale has a range of 0 to 100 points; a higher score indicates greater adherence to the guidelines. The HEI-2010 is composed of twelve groups: nine categories that measure adequacy (total fruit; whole fruit; total vegetables; greens and beans; whole grains; dairy; total protein foods; seafood and plant proteins; fatty acids) and three groups that estimate moderation (refined grains; sodium; empty calories) (Cronbach's $\alpha=0.68)^{(46)}$.

\section{Statistical analyses}

All analyses were conducted via the statistical software package IBM SPSS Statistics for Windows version 19.0
(Graduate Pack, 2010). Descriptive statistics were performed and are presented as means with their SE and frequency distributions. Differences in independent variables (age, sex, ethnicity, marital status, education, occupation, housing, annual income, BMI, language, health status, smoking, drinking alcohol, nutrition knowledge, client type, diet quality of base and total diets) between foodsecure and food-insecure participants were assessed using ANOVA. The Bonferoni post boc test was used to compare two or more independent samples of equal or different sample sizes. Regression models were used to establish associations between food security and demographics, food groups, and diet quality of both base and total diets. Data were reported as OR with $95 \%$ CI. Data were considered significant at $P<0 \cdot 05$.

\section{Results}

Approximately $73 \%$ of clients in our sample demonstrated a lack of food security. Characteristics of the participants according to food security status are presented in Table 1. Mean age of the food-secure and food-insecure clients did not differ significantly (47v. 49 years). Food-insecure clients had lived a shorter duration in the USA and were overweight, compared with the food secure. Food-secure clients had higher annual income and diet quality than did the food insecure $(P<0 \cdot 02)$.

Table 2 indicates the OR of food groups and diet quality (HEI-2010 scores) for food-secure and food-insecure clients. The status of food security was improved if the clients consumed a daily diet (base diet) that contained large amounts of total vegetables, grains, dairy or protein foods $(P<0 \cdot 05)$. Moreover, the probability of food insecurity was reduced by $\geq 1 \cdot 17$-fold when the total dietary intake included the food donations, which were rich in fruits, total vegetables and grains, dairy and protein foods $(P<0.05)$. Thus, consumption of food donations had a greater effect on improving food security status of the clients, particularly due to the intake of fruits, vegetables and protein foods, than when eating the base diet (without the donations) as reflected by the OR values $(P<0.05)$. 
Table 2 Effect of food groups and diet quality, as reflected by HEl-2010 scores*, on food-secure and food-insecure ${ }^{*}$ adult clients ( $n$ 222) from a food pantry and soup kitchen in Central Texas, USA, in September and October 2015ł

\begin{tabular}{|c|c|c|c|c|c|c|}
\hline \multirow[b]{2}{*}{ Variable } & \multicolumn{3}{|c|}{ Food insecure $v$. food secure } & \multicolumn{3}{|c|}{ Food insecure $v$. food secure } \\
\hline & OR§ & $95 \% \mathrm{Cl}$ for OR & $P$ & OR§ & $95 \% \mathrm{Cl}$ for $\mathrm{OR}$ & $P$ \\
\hline & \multicolumn{3}{|c|}{ Base diet } & \multicolumn{3}{|c|}{ Total diet (base diet plus donations) } \\
\hline Food groups & & & & & & \\
\hline Total fruits & - & - & - & -1.19 & $-1.02,1.41$ & 0.026 \\
\hline Total vegetables $\|$ & -0.56 & $-0.36,0.88$ & 0.013 & -1.30 & $-1.08,1.58$ & 0.007 \\
\hline Total grains $\|$ & -1.39 & $-1.03,1.87$ & 0.033 & -0.86 & $-0.75,0.98$ & 0.025 \\
\hline Dairy & -2.59 & $-1 \cdot 09,6 \cdot 11$ & 0.030 & -1.47 & $-1.03,2.09$ & 0.032 \\
\hline $\begin{array}{l}\text { Protein foods - meat and beans } \\
\text { HEl-2010 scores }\end{array}$ & $-0 \cdot 78$ & $-0.64,0.94$ & 0.011 & -1.17 & $-1 \cdot 06,1 \cdot 29$ & 0.002 \\
\hline Total vegetables $\|$ & -0.83 & $-0.73,0.94$ & 0.004 & -1.62 & $-1 \cdot 21,2 \cdot 18$ & 0.001 \\
\hline Whole grains $\|$ & -1.53 & $-1.18,1.99$ & 0.002 & -0.58 & $-0.37,0.92$ & 0.020 \\
\hline Refined grains $\Phi$ & - & - & - & -1.14 & $-1.02,1.26$ & 0.017 \\
\hline Dairy & $-1 \cdot 19$ & $-1.07,1.32$ & 0.001 & $-1 \cdot 15$ & $-1.00,1.32$ & 0.044 \\
\hline Protein foods - meat and beans & -0.89 & $-0.80,0.98$ & 0.021 & - & - & - \\
\hline Sodium \| & $1 \cdot 15$ & $1.06,1.27$ & 0.002 & - & - & - \\
\hline Fatty acids $\mathbb{\|}{ }^{* *}$ & - & - & - & $1 \cdot 18$ & $-1.02,1.36$ & 0.024 \\
\hline
\end{tabular}

The OR increases multiplicatively by $\exp (\beta)$ for every unit increase in the predictor. The reference group is food secure $(\mathrm{OR}=1)$.

*Total Healthy Eating Index-2010 ( $\mathrm{HEl}-2010)$ score range is $0-100$. A higher score reflects greater diet quality ${ }^{(32)}$.

†Food security evaluated with the Core Food Security Module (CFSM). CFSM score ranges between 0 and 10 for a household without children, and from 0 to 18 for a home with children. A lower score represents greater food security ${ }^{(27)}$.

¥Statistical significance is at $P<0.05$.

§OR measures the association between CFSM total score and the predictors (food groups and HEl-2010 scores of the base and total diets), where food secure is the reference. A positive OR indicates greater CFSM score, and thus lower food security. A negative OR reflects lower CFSM score, and thus better food security.

|Controlling for all food groups.

TControlling for all HEl-2010 groups.

${ }^{\star \star}$ Fatty acids $=($ PUFA + MUFA $) / S F A$.

Table 2 also shows that the risk of food insecurity was decreased after eating a base diet of high nutritional quality, specifically containing large proportions of total vegetables, whole grains, dairy or protein foods; but with lesser amounts of sodium $(P<0.05)$. When the total diet (that included the food donations) was of high nutritional quality, the likelihood of food insecurity was minimized due to consuming total vegetables, whole and refined grains, and dairy products abundantly, as well as eating fatty acids sparingly $(P<0.05)$. Thus, the improved diet quality of the total diet (after the addition of the food donations) had a positive influence on food security of the participants $(P<0.05)$.

Both groups encountered barriers that prevented their enrolment in government food assistance programmes. These programmes were well known, as only $2 \%$ of the participants lacked knowledge about programmes such as SNAP. Yet $98 \%$ had been denied approval for enrolment due to being convicted of a crime or not being a citizen (eligibility criteria). Furthermore, $17 \%$ of the total population sample was marginally food secure and only $10 \%$ were fully secure $(P<0 \cdot 001)$. About 40 and $43 \%$ of food pantry and soup kitchen users, respectively, had enough to eat, but it was not always the type of food that they wanted to consume $(P=0 \cdot 04)$. Participants attributed lack of food to a shortage in resources; inability to commute to a store that contained good-quality foods or the type needed; absence of a kitchen and/or defective cooking/ storage facilities (a stove/refrigerator); or experiencing a health issue. Moreover, the majority (88.1\%) of soup kitchen clients had low or very low food security status, compared with $58.1 \%$ of the food pantry recipients $(P<0 \cdot 001)$.

Of the food-insecure clients, $61 \%$ were men; $42 \%$ Caucasians; $56 \%$ single; $15 \%$ divorced, $11 \%$ widowed; and $67 \%$ were homeless. Also, $64 \%$ had annual income $<\$$ US 1000, 29\% were eligible to receive Supplemental Security monthly income (SSI) and $60 \%$ went to a soup kitchen $(P<0 \cdot 01)$. In contrast, two-thirds of the food secure were women and had an annual income $>$ \$US 1000. Only $10 \%$ were eligible to receive SSI benefits $(P<0 \cdot 01)$. Of the food secure, $22 \%$ were Blacks and $47 \%$ were Hispanics; $42 \%$ were married; $78 \%$ lived in a residence; and $42 \%$ received free food donations from the food pantry $(P<0 \cdot 01)$. More than $80 \%$ of the food-secure and food-insecure clients were unemployed.

According to mean CFSM scores, food insecurity was significantly higher among clients who had a health condition (7.9 (SD 0.3)) and smoked cigarettes (8.0 (SD 0.3)) than among those who were healthy (6.1 (SD 0.4)) or did not smoke (6.8 (SD 0.3); $P<0.05)$. In addition, English speakers $(7 \cdot 7$ (SD 0.2)) and participants who had low nutrition knowledge (7.9 (SD 0.3)) and utilized a soup kitchen (7.9 (SD 0.2)) exhibited lower food security status than did individuals who spoke Spanish (5.8 (SD 0.7)), had good nutrition knowledge (6.9 (sD 0.3)) or attended a food pantry (6.8 (sD 0.4); $P<0.05$; Fig. 1). Furthermore, Table 3 shows the effect of demographic and socio-economic characteristics on food security status of clients. The sample who was food insecure was primarily women, had 


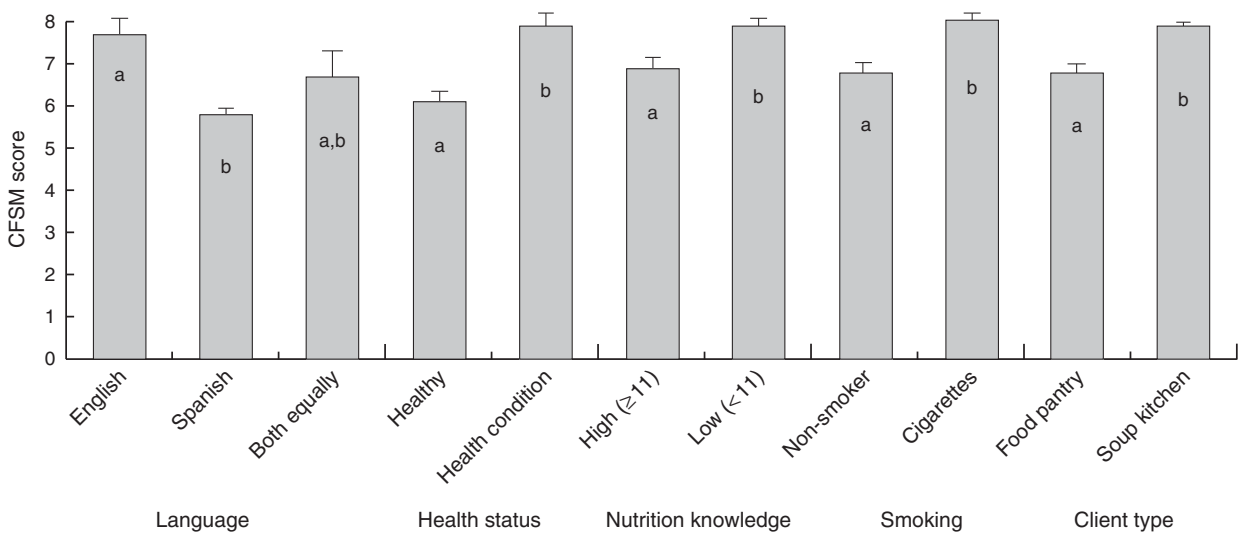

Fig. 1 Food security, evaluated as mean Core Food Security Module (CFSM) scores* with their standard errors represented by vertical bars, according to language, health status, nutrition knowledge, smoking and client type, of adult clients $(n 222)$ from a food pantry and soup kitchen in Central Texas, USA, in September and October $2015 .{ }^{a, b}$ Mean values within a category with unlike superscript letters were significantly different $(P \leq 0.05)$. ${ }^{*} \mathrm{CFSM}$ score ranges between 0 and 10 for a household without children, and from 0 to 18 for a home with children. A higher score reflects greater food insecurity ${ }^{(27)}$

Table 3 Effect of demographic and socio-economic characteristics on food security status* of adult clients $(n 222)$ from a food pantry and soup kitchen in Central Texas, USA, in September and October 2015†

\begin{tabular}{|c|c|c|c|}
\hline \multirow[b]{2}{*}{ Characteristic } & \multicolumn{3}{|c|}{ Food insecure $v$. food secure } \\
\hline & OR & $95 \% \mathrm{Cl}$ for $\mathrm{OR}$ & $P$ \\
\hline Sex (woman)§ & 3.14 & $1.69,5.86$ & 0.000 \\
\hline Household size§ & 1.37 & $1.18,1.59$ & 0.000 \\
\hline Number of children in household§ & 1.52 & $1.21,1.91$ & 0.000 \\
\hline Low income§ & 2.43 & $1.32,4.49$ & 0.004 \\
\hline Below poverty level (\$US 11880/year)§ & $2 \cdot 88$ & $1.44,5.73$ & 0.003 \\
\hline Ineligibility to receive Supplemental Security Income§ & 3.68 & $1.48,9 \cdot 13$ & 0.005 \\
\hline Smoking $\|$ & 3.08 & $1.51,6.27$ & 0.002 \\
\hline Health condition $\|$ & $4 \cdot 31$ & $2 \cdot 19,8 \cdot 47$ & 0.000 \\
\hline Drinking alcohol§ & $2 \cdot 17$ & $1.07,4.42$ & 0.03 \\
\hline \multicolumn{4}{|c|}{$\begin{array}{l}\text { The OR increases multiplicatively by exp }(\beta) \text { for every unit increase in the predictor. Reference group is food secure }(\mathrm{OR}=1) \text {. } \\
\text { *Food security evaluated with the Core Food Security Module (CFSM). CFSM score ranges between } 0 \text { and } 10 \text { for a household without } \\
\text { children, and from } 0 \text { to } 18 \text { for a home with children. A lower score represents greater food security } \\
\text { †Statistical significance is at } P<0.05 \text {. } \\
\text { fOR measures the association between CFSM total score and the predictors (demographic and socio-economic characteristics), with } \\
\text { food secure as the reference. A positive OR indicates greater CFSM score, and thus lower food security. } \\
\text { \$Controlling for all demographic and socio-economic characteristics. } \\
\text { ॥ Smoking and health status were included in the model. }\end{array}$} \\
\hline
\end{tabular}

a larger family and/or children and low income, was below the poverty threshold or not eligible to receive SSI benefits $(P<0 \cdot 01)$. The probability of becoming food insecure increased if the clients smoked, had a health condition or drank alcohol $(P<0.05)$.

\section{Discussion}

These results suggest that the level of food insecurity of the present sample (73\%) is higher than that reported for Texas by the Economic Research Service $(14 \cdot 3 \%)^{(47)}$ or by the study in West Texas by Murimi et al. (63\%) ${ }^{(48)}$. Furthermore, numerous studies in other regions in the USA have reported the incidence of food insecurity to be lower than our findings. These included $7.8 \%$ of 230 elderly in Alabama $^{(49)}, 30 \%$ of 435 adults in Massachusetts ${ }^{(50)}, 42 \cdot 7 \%$ of 16651 poor households in Boston ${ }^{(51)}$ and $55.9 \%$ of 220 low-income and homeless families in Washington, $\mathrm{DC}^{(52)}$. One might think that it could be related to the large border of Texas with Mexico, but even higher levels have been observed in Rhode Island in which $94 \%$ of 252 homeless men and women had low levels of food security in 2015. Of these, $55 \%$ used SNAP benefits, shelters, food pantries and/or soup kitchens for sources of food ${ }^{(53)}$.

Additionally, figures similar to our findings have been reported in Connecticut in which $76 \%$ of 200 Hispanic immigrants were food insecure. Of these, $37 \%$ used food pantries and/or soup kitchens ${ }^{(54)}$. Lower levels of food insecurity prevalence have been observed in Canada, with a prevalence of $4 \%$ in 81581 households ${ }^{(55)}$, increasing to $16.9 \%$ in seventy-seven Columbian immigrants ${ }^{(56)}$. In contrast, other surveys in Canadians have indicated even higher rate of low food security. For instance, $70 \%$ of 
120000 users of food assistance programmes aged $\geq 12$ years $^{(57)}$ and $75 \%$ of 317 low-income houses ${ }^{(58)}$ were reported to be food insecure in 2014 and 2012, respectively.

The current research found that consumption of food donations improved the food security status of the clients; this is due primarily to the greater intake of fruits, vegetables and protein foods $(P<0 \cdot 05)$. A study conducted by Miewald et al. supports our results, in which food-secure individuals participating in the Food Box programme (distributes fruits and vegetables) in Ohio had greater intakes of fruits and vegetables than food-insecure individuals $(5.0 v .3 .6 \text { servings, } P<0.001)^{(59)}$. In addition, Robaina and Martin documented that the food secure who obtained food benefits from government and nongovernment agencies were more likely to consume fruits and vegetables by twofold, compared with the insecure $^{(60)}$. Others have found that the availability of fruits and vegetables in food pantries increased their clients' intake by one serving per day ${ }^{(61,62)}$. These outcomes are supported by the present results, in which inclusion of vegetables in the food donation improved diet quality by 1.6-fold ( $P=0 \cdot 001)$.

Our findings also indicate that food-secure clients consumed a diet with a higher nutrition quality than did the food insecure. Food security was increased by receiving food donations and this extra food improved the quality of their total diet. Comparable outcomes were reported by the 2003-2010 National Health and Nutrition Examination Survey (NHANES) ${ }^{(63)}$ in which diet quality was higher in the 4645 food-secure than the 3688 food-insecure adults receiving SNAP benefits (HEI-2010 score $47 v$. 44, $P=0 \cdot 001)$. Yet their HEI-2010 score was lower for both food-secure and food-insecure adults when compared with our sample $(67 v .63, P<0.001)^{(63)}$. Huet et al. ${ }^{(64)}$ found similar findings in a study that assessed food security and nutrition quality of 1901 Inuit families in Canada. Two-thirds of the participants lacked food security, and they had lower diet quality than the food secure $(52 \cdot 6$ v. 55.3, $P<0.001)$.

Moreover, a stratified sample from the Delta Nutrition Intervention Research Initiative explored dietary patterns and food security in 1607 American households ${ }^{(65)}$. The mean HEI was higher among food-secure than foodinsecure men and women (60.6 v . 57.4, $P<0 \cdot 001)$. Compared with the food secure, food-insecure participants had lower mean scores for dairy foods (4.2 v. 3.2), vegetables (5.6 v. 4.4), cholesterol $(7 \cdot 4 v .6 \cdot 8)$ and lack of sodium intake $(7.1 v .6 .3 ; P<0.05)^{(65)}$. Results of Champagne et al. ${ }^{(65)}$ and other studies support our conclusion ${ }^{(56,66-68)}$ that food security is improved when consuming a diet of high nutritional quality that is rich in fruits, vegetables, whole grains, dairy and protein foods, and low in fats and sodium.

Possible reasons for food insecurity in our participants were lack of resources and good-quality and/or preferred foods in the grocery store, and inadequate storage and/or cooking facilities (such as living in a shelter or being homeless). Moreover, individuals without homes may not use food pantries since they lack storage/cooking locations and may depend solely on attending soup kitchens to obtain food. In a survey that assessed characteristics of twenty-two food-insecure users of a soup kitchen aged 28-80 years, one-quarter did not have a kitchen and/or a storage facility such as a refrigerator. Those authors suggested that the inability to store or cook food contributed to the negative eating behaviours observed (consumption of fast and convenience foods) ${ }^{(69)}$. In addition, Nord ${ }^{(70)}$ observed that $4 \%$ of food-insecure 13078 elderly and 59203 adult persons lacked availability of food at home. The absence of food was attributed to inability to cook, shop or go to the grocery store; lack of having a working stove; and being sick or on a special diet ${ }^{(70)}$. Results of Wicks et al. ${ }^{(69)}$ and Nord ${ }^{(70)}$ support our findings that lack of housing, storage and/or cooking facilities were factors that increased food insecurity and reduced the ability to prepare a homemade meal.

The majority of our clients did not lack knowledge about the availability of public food assistance programmes such as SNAP but could not enrol in them due to conviction of a crime or lack of citizenship (eligibility criteria). In 2015, Iglesias-Rios et al. reported that Hispanics who did not hold citizenship were 1.3 times more likely to become food insecure than those with citizenship $(P<0.05)$, primarily due to their inability to obtain benefits from charitable networks ${ }^{(71)}$. Some organizations also require food recipients to acquire identification cards and proof of income or residence at the time of donation ${ }^{(72)}$. Other barriers to utilizing food assistance programmes may be inconvenient times of donation and long lines to obtain the food ${ }^{(58)}$. Solving these logistical issues might increase the probability of improving food insecurity in the poverty stricken.

The present study found that the food-insecure clients had very low incomes $(P<0.05)$. This finding is in agreement with that of Kushel et al., who reported that an annual income lower than $100 \%$ of the poverty level was found among $27.2 \%$ of 7659 households who were food insecure ${ }^{(51)}$. Our data indicate that food security was increased by two-, three- and fourfold by being lowincome, below the poverty level (\$US 11880/year) and/ or ineligible to obtain SSI benefits, respectively $(P<0 \cdot 01)$. Hernandez observed that living below $200 \%$ of the federal poverty threshold increased probability of food insecurity by onefold $(P<0.05)^{(73)}$. In addition, Vozoris and Tarasuk found that individuals who lacked financial resources and/or did not own a house were at higher risk for becoming food insecure by about one- and twofold, respectively $(P<0.05)^{(55)}$. Other investigations ${ }^{(64,69,74-79)}$ have published similar findings that limited resources are a major contributor to food insecurity in the low-income population. 
In the current research, women had increased risk for food insecurity by threefold more than men $(P<0 \cdot 001)$. Also, the level of food security was lower in Caucasians and divorced, widowed or single clients than in Hispanic or married participants. A national survey supports the present findings in which lack of food security was higher in women than men $(10.4 v .9 .9 \%)$, as well as in those who were single $(12.9 \%)$ and divorced or separated $(21.3 \%)$ compared with those married $(6.5 \% ; P<0.05)^{(80)}$. Similar results were observed in low-income, tri-ethnic Americans ${ }^{(51)}$, American immigrants from Mexico ${ }^{(8)}$ and Puerto Rico ${ }^{(54)}$, and Canadians who had migrated from Columbia ${ }^{(56)}$.

In our study, the presence of two or more family members and/or children in the household increased the probability of food insecurity by $1.4-$ and 1.5 -fold, respectively $(P<0 \cdot 001)$. A cross-sectional study ${ }^{(8)}$ in 2013 showed that $80 \%$ of fifty Hispanic mothers who had an average of three children were food insecure. McIntyre et $a l .{ }^{(68)}$ also reported that $58.3 \%$ of 141 low-income mothers in Canada lacked food security; however their children were considered food secure. It is believed that the mothers saved the food for the children at the expense of themselves ${ }^{(68)}$. These reports agree with our research that the presence of adults and other members in the household reduces food security.

In the present investigation, clients who smoked, drank alcohol and had a health problem were more likely to have low food security status than did non-smokers, nondrinkers and healthy individuals by three-, four- and twofold, respectively $(P<0.05)$. The 1999-2008 NHANES $^{(71)}$ reported that $61 \%$ of 6681 Latinos lived below $185 \%$ of the poverty line, $36.7 \%$ lacked food security and $22 \%$ smoked cigarettes. About $26 \%$ of the food insecure were smokers ${ }^{(71)}$. Dixon et al. ${ }^{(81)}$ also observed that $40 \cdot 0$ and $37.9 \%$ of 599 food-insecure men and women smoked cigarettes and drank alcohol, respectively. Furthermore, the 1999-2004 NHANES $^{(82)}$ showed that 22.4 and $21.7 \%$ of 5094 low-income men and women had hypertension and hyperlipidaemia, respectively. These health problems significantly increased the risk of food insecurity by onefold $(P<0.05)^{(82)}$. Mojtabai ${ }^{(83)}$, Rosenblum et $a{ }^{(84)}$ and Starkey et al. ${ }^{(85)}$ observed comparable results. Thus, drinking alcohol, smoking and having a health problem appear to be prevalent in the food insecure.

The current research determined that food-insecure clients had lower nutrition knowledge level than did those with food security $(P<0 \cdot 05)$. In 2012, Wang and Chen reported that men and women who had greater nutrition knowledge purchased healthier foods, and were more likely to meet the dietary recommendations for fruits, vegetables and whole grains, than those who had low levels ${ }^{(86)}$. The lack of nutrition knowledge in low-income individuals may negatively affect their eating behaviours ${ }^{(87)}$, leading to an increase in food insecurity.
The current study observed that the clients who spoke English had better food security status than did those who spoke Spanish only. As Hispanics become more acculturated, they may transition to eating more Westernized diets that are rich in fast and processed foods. In contrast, Dhokarh et al. observed that low food security was more prevalent among low-income Puerto-Rican immigrant women who spoke both English and Spanish than in Spanish-only speakers $(68 v .32 \%, P<0 \cdot 05)^{(54)}$. Nevertheless, findings of Iglesias-Rios et al. ${ }^{(71)}$ provide support to our results in which Hispanic adults, who were fluent primarily in Spanish, were more likely to become food insecure by odds of 1.24 compared with those who conversed in English. These authors proposed that a language barrier might reduce the opportunity of obtaining an occupation and accessing government food assistance programmes such as SNAP or WIC ${ }^{(71)}$. Other studies ${ }^{(88-91)}$ are in agreement with the current outcomes.

\section{Conclusions}

Low food security was prevalent in about three-quarters of the clients using food pantries and soup kitchens surveyed in Central Texas, USA. Major reasons cited were lack of financial resources, poor-quality foods in the store, and limited or absent storage and/or cooking facilities. Women or participants who were below the poverty threshold and/or ineligible to receive SSI benefits were at the greatest risk of food insecurity. As expected, food-secure clients' diet quality was higher than that of the food insecure. The addition of food donations to the base diet resulted in consumption of a total diet that was rich in fruits, total vegetables and grains, dairy and protein foods. Consequently, the improved quality of the total diet (after the addition of the food donations) had a positive influence on food security of the participants.

Policy makers should develop strategies to ensure better accessibility of low-income individuals to public food assistance. Organizations in the community should collaborate to support food emergency programmes by offering resources such as money and food donations to sustain the stability of operations of food rescue nutrition. In addition, food assistance programmes should strive to offer a variety of healthy and tasty foods in adequate quantities to provide optimum diet quality.

\section{Acknowledgements}

Financial support: This research was supported by Bess Heflin Centennial Professorship from the Department of Human Ecology, The University of Texas at Austin. The funder had no role in the design, analysis or writing of this article. Conflict of interest: There is no conflict of interest. 
Authorship: T.Y.M. was a PhD student under the supervision of J.H.F.-G. T.Y.M. and J.H.F.-G. designed the study and formulated the questions. T.Y.M. carried out the research (data collection) and analysed the data. Both authors wrote the article which was supervised by J.H.F.-G. Ethics of human subject participation: This study was conducted according to the guidelines laid down in the Declaration of Helsinki and all procedures involving human subjects were approved by the Institutional Review Board at the University of Texas at Austin. Written informed consent was obtained from all subjects.

\section{References}

1. Vijayaraghavan M, Jacobs E, Seligman H et al. (2011) The association between housing instability, food insecurity, and diabetes self-efficacy in low-income adults. $J$ Health Care Poor Underserved 22, 1279-1291.

2. Food and Agriculture Organization of United Nations (2015) The state of food insecurity in the world 2015. Meeting the 2015 international hunger targets: taking stock of uneven progress. http://www.fao.org/3/a-i4646e.pdf (accessed August 2018).

3. Food and Agriculture Organization of United Nations (2017) The state of food security and nutrition in Europe and Central Asia 2017. http://www.fao.org/3/a-i8194e.pdf (accessed August 5, 2018).

4. PROOF Food Insecurity Policy Research (2018) Latest household food insecurity data now available. http://proof. utoronto.ca/new-data-available/ (accessed August 2018).

5. Gundersen C, Kreider B \& Pepper J (2011) The economics of food insecurity in the United States. Appl Econ Perspect Policy 33, 281-303.

6. Coleman-Jensen A, Rabbitt M, Gregory C et al. (2016) Statistical Supplement to Household Food Security in the United States in 2015. Economic Research Report no. ERR-215. Washington, DC:US Department of Agriculture, Economic Research Service.

7. Metallinos-Katsaras E, Must A \& Gorman K (2012) A longitudinal study of food insecurity on obesity in preschool children. J Acad Nutr Diet 112, 1949-1958.

8. Nalty C, Sharkey J \& Dean W (2013) Children's reporting of food insecurity in predominately food insecure households in Texas border colonias. Nutr J 12, 15-23.

9. Nutrition.gov (2014) Food Assistance Programs. http://www. nutrition.gov/food-assistance-programs (accessed May 2014).

10. Mabli J \& Worthington J (2014) Supplemental Nutrition Assistance Program participation and child food security. Pediatrics 133, 610-619.

11. GivingWay (2017) Banco de Alimentos de Buenos Aires (Food Bank of Buenos Aires). https://www.givingway.com/ organization/fundacin-banco-de-alimentos (accessed December 2017).

12. Food Angel by Bo Charity Foundation (2017) Food Angel Rescue and Assistance Program. http://www.foodangel.org.hk/ en/about.php\#/how_we_work (accessed December 2017).

13. Food from the Heart (2017) Homepage. https://foodheart.org/ (accessed November 2017).

14. Leket Israel, the National Food Bank (2016) Food Waste and Rescue in Israel. The Economic, Social and Environmental Impact. National Report. Tel Aviv: BDO Israel.

15. Wa'hab (2017) Homepage. https://www.wahab.qa/ (accessed November 2017).

16. University of Sheffield, Food Security and Food Justice (2016) A Food Bank in Africa. https://foodsecurityfoodjustice.com/ 2016/11/06/a-food-bank-in-africa/ (accessed August 2018).
17. The Trussell Trust (2017) End of year stats. https://www. trusselltrust.org/news-and-blog/latest-stats/end-year-stats/ (accessed November 2017).

18. Instock (2017) Homepage. https://www.instock.nl/en/ (accessed October 2017).

19. Bendix R (2014) Taste of trash: the politics of refuse. In Political Meals, pp. 132-142 [R Bendix and M Fenske, editors]. Berlin: University of Göttingen.

20. SecondBite: food for people in need (2017) Homepage. https://www.secondbite.org (accessed November 2017).

21. Second Harvest Food Rescue (2018) Homepage. https://secondharvest.ca/ (accessed August 2018).

22. Feeding America (2015) Feeding families, feeding hope. 2015 Annual report. http://www.feedingamerica.org/about-us/aboutfeeding-america/annual-report/2015-feeding-america-annual. pdf (accessed June 2016).

23. Donate Don't Dump (2013) About us. http://donatedontdump. net/about (accessed August 2016).

24. Capital Area Food Bank of Texas (2016) About us. http://www. austinfoodbank.org/about-us/ (accessed July 2016).

25. Capital Area Food Bank of Texas (2017) Annual Report 2016-2017. http://ctxfoodbank.org/2017annualreport/ (accessed July 2018).

26. Will J \& Milligan T (2015) Toward an understanding of food pantry food recipients and the agencies that serve them. J Appl Soc Sci 9, 65-74.

27. Kempson K, Keenan D, Sadani P et al. (2003) Maintaining food sufficiency: coping strategies identified by limitedresource individuals versus nutrition educators. J Nutr Educ Behav 35, 179-188.

28. Hoisington A, Shultz J \& Butkus S (2002) Coping strategies and nutrition education needs among food pantry users. J Nutr Educ Behav 34, 26-33.

29. Duffy P, Hallmark G, Molnar J et al. (2002) Food security of low-income single parents in East Alabama: use of private and public programs in the age of welfare reform. South Rural Sociol 18, 48-81.

30. Ahluwalia I, Dodds J \& Baligh M (1998) Social support and coping behaviors of low-income families experiencing food insufficiency in North Carolina. Health Educ Behav 25, 599-612.

31. Bowering J, Clancy K \& Poppendieck J (1991) Characteristics of a random sample of emergency food program users in New York: II. Soup kitchens. Am J Public Health 81, 914-917.

32. Clancy K, Bowering J \& Poppendieck J (1991) Characteristics of a random sample of emergency food program users in New York: I. Food pantries. Am J Public Health 81, 911-914.

33. Morrissey T, Jacknowitz A \& Vinopal K (2014) Local food prices and their associations with children's weight and food security. Pediatrics 133, 422-430.

34. Nichols-Casebolt A \& Morris P (2002) Making ends meet: private food assistance and the working poor. J Soc Serv Res 28, 1-22.

35. Shanks C, Ahmed S, Smith T et al. (2015) Availability, rice, and quality of fruits and vegetables in 12 rural Montana counties, 2014. Prev Chronic Dis 12, E128.

36. High Level Panel of Experts on Food Security and Nutrition (2011) Price volatility and food security. A report by the High Level Panel of Experts on Food Security and Nutrition of the Committee on World Food Security, Rome 2011. http:// www.fao.org/fileadmin/user_upload/hlpe/hlpe_documents/ HLPE-price-volatility-and-food-security-report-July-2011.pdf (accessed June 2014).

37. Nackers L \& Appelhans B (2013) Food insecurity is linked to a food environment promoting obesity in households with children. J Nutr Educ Behav 45, 780-784.

38. Klohe-Lehman D, Freeland-Graves J, Anderson E et al. (2006) Nutrition knowledge is associated with greater 
weight loss in obese and overweight low-income mothers. J Am Diet Assoc 106, 65-75.

39. Tabbakh T \& Freeland-Graves J (2016) The home environment: a mediator of nutrition knowledge and diet quality in adolescents. Appetite 105, 46-52.

40. Bickel G, Nord M, Price C et al. (2000) Guide to Measuring Household Food Security, Revised 2000. Alexandria, VA: US Department of Agriculture, Food and Nutrition Service.

41. George G, Milani T, Hanss-Nuss H et al. (2004) Development and validation of a semi-quantitative food frequency questionnaire for young adult women in the southwestern United States. Nutr Res 24, 29-43.

42. Epi Info (2015) FoodWorks 8 Professional, Version 17. Long Valley, NJ: The Nutrition Company.

43. Choose MyPlate (2011) Homepage. http://www.choosemyplate.gov/ (accessed June 2014).

44. US Department of Health and Human Services \& US Department of Agriculture (2015) Dietary Guidelines for Americans 2015-2020, 8th ed. http://health.gov/dietary guidelines/2015/guidelines/ (accessed April 2016).

45. Guenther P, Casavale K, Reedy J et al. (2013) Update of the Healthy Eating Index: HEI-2010. J Acad Nutr Diet 113, 569-580.

46. Guenther P, Kirkpatrick S, Reedy J et al. (2014) The Healthy Eating Index-2010 is a valid and reliable measure of diet quality according to the 2010 Dietary Guidelines for Americans. J Nutr 144, 399-407.

47. Coleman-Jensen A, Rabbitt M, Gregory C et al. (2017) Household Food Security in the United States in 2016. Economic Research Report no. ERR-237. Washington, DC: US Department of Agriculture, Economic Research Service; available at https://www.ers.usda.gov/webdocs/publications/ 84973/err-237.pdf? v $=42979$

48. Murimi M, Kanyi M, Mupfudze T et al. (2016) Prevalence of food insecurity in low-income neighborhoods in West Texas. J Nutr Educ Behav 48, 625-630.

49. Locher J, Ritchie C, Robinson C et al. (2008) A multidimensional approach to understanding under-eating in homebound older adults: the importance of social factors. Gerontologist 48, 223-234.

50. Webb A, Schiff A, Currivan D et al. (2008) Food Stamp Program participation but not food insecurity is associated with higher adult BMI in Massachusetts residents living in low-income neighbourhoods. Public Health Nutr 11, $1248-1255$.

51. Kushel M, Gupta R, Gee L et al. (2006) Housing instability and food insecurity as barriers to health care among lowincome Americans. J Gen Intern Med 21, 71-77.

52. Gundersen C, Weinreb L, Wehler C et al. (2003) Homelessness and food insecurity. J Hous Econ 12, 250-272.

53. Martins D, Gorman K, Miller R et al. (2015) Assessment of food intake, obesity, and health risk among the homeless in Rhode Island. Public Health Nurs 32, 453-461.

54. Dhokarh R, Himmelgreen D, Peng Y et al. R (2011) Food insecurity is associated with acculturation and social networks in Puerto Rican households. J Nutr Educ Behav $\mathbf{4 3}$ 288-294.

55. Vozoris N \& Tarasuk V (2003) Household food insufficiency is associated with poorer health. J Nutr 133, 120-126.

56. Rush T, Irwin J, Stitt L et al. (2007) Food insecurity and dietary intake of immigrant food bank users. Can J Diet Pract Res 68, 73-78.

57. Tarasuk V, Dachner N \& Loopstra R (2014) Food banks, welfare, and food insecurity in Canada. Br Food J 116, 1405-1417.

58. Loopstra R \& Tarasuk V (2012) The relationship between food banks and household food insecurity among lowincome Toronto families. Can Public Policy 38, 497-514.

59. Miewald C, Holben D \& Hall P (2012) Role of a food box program in fruit and vegetable consumption and food security. Can J Diet Pract Res 73, 59-65.
60. Robaina K \& Martin K (2013) Food insecurity, poor diet quality, and obesity among food pantry participants in Hartford, CT. J Nutr Educ Behav 45, 159-164.

61. Martin K, Wu R, Wolff M et al. (2013) A novel food pantry program: food security, self-sufficiency, and diet-quality outcomes. Am J Prev Med 45, 569-575.

62. Keller-Olaman S, Edwards V \& Elliott S (2005) Evaluating a food bank recipe-tasting program. Can J Diet Pract Res $\mathbf{6 6}$, 183-186.

63. Nguyen B, Shuval K, Bertmann F et al. (2015) The Supplemental Nutrition Assistance Program, food insecurity, dietary quality, and obesity among US adults. Am J Public Health 105, 1453-1459.

64. Huet C, Rosol R \& Egeland G (2012) The prevalence of food insecurity is high and the diet quality poor in Inuit communities. J Nutr 142, 541-547.

65. Champagne C, Casey P, Connell C et al. (2007) Poverty and food intake in rural America: diet quality is lower in food insecure adults in the Mississippi Delta. J Am Diet Assoc 107, 1886-1894.

66. Nnakwe N (2008) Dietary patterns and prevalence of food insecurity among low-income families participating in community food assistance programs in a Midwest town. Fam Consum Sci Res J 36, 229-242.

67. Kirkpatrick S \& Tarasuk V (2008) Food insecurity is associated with nutrient inadequacies among Canadian adults and adolescents. J Nutr 138, 604-612.

68. McIntyre L, Glanville N, Raine K et al. (2003) Do lowincome lone mothers compromise their nutrition to feed their children? CMAJ 168, 686-691.

69. Wicks R, Trevena L \& Quine S (2006) Experiences of food insecurity among urban soup kitchen consumers: insights for improving nutrition and well-being. J Am Diet Assoc 106, 921-924.

70. Nord M (2003) Measuring food security of elderly persons. Fam Econ Nutr Rev 15, 33-46.

71. Iglesias-Rios L, Bromberg J, Moser R et al. (2015) Food insecurity, cigarette smoking, and acculturation among Latinos: data from NHANES 1999-2008. J Immigr Minor Health 17, 349-357.

72. Gany F, Bari S, Crist M et al. (2013) Food insecurity: limitations of emergency food resources for our patients. $J$ Urban Health 90, 552-558.

73. Hernandez D (2015) The impact of cumulative family risks on various levels of food insecurity. Soc Sci Res 50, 292-302.

74. Lee J, Johnson M, Brown A et al. (2011) Food security of older adults requesting older Americans Act Nutrition Program in Georgia can be validly measured using a short form of the US Household Food Security Survey Module. J Nutr 141, 1362-1368.

75. Berner M, Ozer T \& Paynter S (2008) A portrait of hunger, the social safety net, and the working poor. Policy Stud J36, 403-420.

76. Cook J \& Frank D (2008) Food security, poverty, and human development in the United States. Ann N Y Acad Sci 1136, 193-209.

77. Michalski J (2003) The economic status and coping strategies of food bank users in the Greater Toronto Area. Can J Urban Res 12, 275-298.

78. Jensen H (2002) food insecurity and the food stamp program. Am J Agric Econ 84, 1215-1228.

79. Reschovsky J (1991) The emergency food relief system: an empirical study. J Consum Aff 25, 258-277.

80. Che J \& Chen J (2001) Food insecurity in Canadian households. Health Rep 12, 11-22.

81. Dixon L, Winkleby M \& Radimer K (2001) Dietary intakes and serum nutrients differ between adults from foodinsufficient and food-sufficient families: Third National Health and Nutrition Examination Survey, 1988-1994. J Nutr 131, 1232-1246. 
82. Seligman H, Laraia B \& Kushel M (2010) Food insecurity is associated with chronic disease among low-income NHANES participants. J Nutr 140, 304-310.

83. Mojtabai R (2005) Perceived reasons for loss of housing and continued homelessness among homeless persons with mental illness. Psychiatr Serv 56, 172-178.

84. Rosenblum A, Magura S, Kayman D et al. (2005) Motivationally enhanced group counseling for substance users in a soup kitchen: a randomized clinical trial. Drug Alcohol Depend 80, 91-103.

85. Starkey L, Kuhnlein H \& Gray-Donald K (1998) Food bank users: sociodemographic and nutritional characteristics. CMAJ 158, 1143-1149.

86. Wang Y \& Chen X (2012) Between-group differences in nutrition- and health-related psychosocial factors among US adults and their associations with diet, exercise, and weight status. J Acad Nutr Diet 112, 486-498.
87. Appelhans B, Waring M, Schneider K et al. (2014) Food preparation supplies predict children's family meal and home-prepared dinner consumption in low-income households. Appetite 76, 1-8.

88. Ayala G, Baquero B \& Klinger S (2008) A systematic review of the relationship between acculturation and diet among Latinos in the United States: implications for future research. J Am Diet Assoc 108, 1330-1344.

89. Satia J (2010) Dietary acculturation and the nutrition transition: an overview. Appl Physiol Nutr Metab 35, 219-223.

90. Pérez-Escamilla R (2009) Dietary quality among Latinos: is acculturation making us sick? J Am Diet Assoc 109, 988-991.

91. Satia-Abouta J (2003) Dietary acculturation: definition, process, assessment, and implications. Int J Hum Ecol $\mathbf{4}$, $71-86$. 